Jurnal Laut Khatulistiwa, Vol. 4 No. 1 (Febuari, 2021), Hal. 40-48.

ISSN : 2614-6142 (Printed), 2614-8005 (Online)

http://jurnal.untan.ac.id/index.php/lk

JURNAL LAUT

KHATULISTIWA

\title{
Kondisi Arus Musim Barat di Perairan Pantai Kijing Kabupaten Mempawah Kalimantan Barat
}

\section{West Monsoon Current Conditions at Kijing Beach, Mempawah Regency, West Kalimantan}

\author{
Fitriani ${ }^{1 *}$, Muliadi1, Risko² \\ 1Program Studi Geofisika, FMIPA Universitas Tanjungpura, Pontianak, Indonesia \\ ${ }^{2}$ Laboratorium Ilmu Kelautan, FMIPA Universitas Tanjungpura, Pontianak, Indonesia \\ ${ }^{*}$ E-mail : fitrianijingga30@gmail.com
}

Received : 10 October 2019; Accepted: 19 November 2019

Published: 29 February (C) Author(s) 2020. This article is open access

\begin{abstract}
Hydrodinamic model Resources Management Associates- 2 (RMA-2) was applied to study current conditions at Kijing beach. The purpose of this research is to analys how the current conditions are in the peak conditions of the west monsoon. Model input is tidal elevation data given in the boundary of the model, bathymetry and wind. Model verification is done by comparing the results of the model with measurements in the field, which shows an elevation Root Mean Square Error (RMSE) value of 0,192 and current is 0,019. The RMSE value for elevation shows an estimate that matches the measurement data, while at the current velocity the model results have a smaller estimate than the measurement data. Based on the simulation model results, the lowest and highest sea level elevation in the west season is $-0,7105$ below the mean sea level and 0,9306 $\mathrm{m}$ above the mean sea level. The speed and direction of the current at low tide ranges from 0,004 to 0,016 with the current direction inclined northwest to east and at the highest tide ranges from 0,033 to 0,034 with the direction inclined to the east-southeast. Furthermore, the velocity and direction of the current at tide towards the low tide ranges from 0,044 to 0,048 with the direction inclined to the eastsoutheast, and at low tide the lowest is 0,046 to 0,053 is also east-southeast direction.
\end{abstract}

Keywords : Sea surface elevation, current, Kijing Beach, RMA-2

\begin{abstract}
Abstrak
Model Hidrodinamika Resources Management Associates- 2 (RMA-2) diaplikasikan untuk mempelajari kondisi arus di perairan pantai Kijing. Tujuan penelitian ini adalah untuk mengkaji bagaimana kondisi arus pada kondisi puncak musim barat. Masukan model adalah data elevasi pasang surut yang diberikan pada bagian batas model, data batimetri perairan serta data angin. Verifikasi model dilakukan dengan membandingkan hasil model terhadap pengukuran di lapangan yang diperoleh nilai Root Mean Square Error (RMSE) elevasi 0,192 dan arus 0,019. Nilai RMSE untuk elevasi menunjukkan perkiraan yang sesuai dengan data pengukuran, sedangkan pada kecepatan arus hasil model memiliki perkiraan yang lebih kecil dari data pengukuran. Berdasarkan hasil simulasi model, elevasi muka air laut terendah dan tertinggi pada musim barat sebesar -0,7105 dibawah tinggi muka air laut rata-rata dan 0,9306 m diatas tinggi muka air laut rata-rata. Kecepatan dan arah arus saat surut menuju pasang berkisar antara 0,004 s.d. 0,016 dengan arah cenderung ke barat laut hingga timur dan saat pasang tertinggi berkisar antara 0,033 s.d. 0,034 dengan arah bergerak ke timur tenggara. Selanjutnya kecepatan dan arah arus saat pasang menuju surut berkisar antara 0,044 s.d. 0,048 dengan arah bergerak ke timur tenggara, dan saat surut terendah 0,046 s.d. 0,053 juga arah timur tenggara.
\end{abstract}

Kata kunci : Elevasi muka air laut, arus, Perairan Pantai Kijing, RMA-2 
Jurnal Laut Khatulistiwa, Vol. 4. No. 1 (Febuari, 2021), Hal. 40-48.

\section{Pendahuluan}

Pantai Kijing terletak di Kabupaten Mempawah Kalimantan Barat secara geografis berada di $0,413^{\circ}-0,574^{\circ}$ lintang utara (LU) dan $108,94^{\circ}-108,79^{\circ}$ bujur timur (BT). Perairan Pantai Kijing memiliki peranan penting dalam bidang kehidupan sosial dan ekonomi, dikarenakan wilayah perairan ini sangat banyak digunakan untuk berbagai aktivitas masyarakat seperti industri, perikanan, pertambakan, pemukiman serta pariwisata. Untuk menunjang aktivitas masyarakat tersebut maka Perairan Pantai Kijing termasuk dalam rencana pengembangan wilayah pesisir dan laut di Kabupaten Mempawah.

Rencana pengembangan wilayah pesisir dan laut yang akan dilakukan adalah pembangunan Pelabuhan Internasional sebagai pengembangan dari Pelabuhan Dwikora Pontianak yang dianggap paling layak, berdasarkan studi kelayakan tahun 2010 oleh Kementerian Perhubungan Ditjen Perhubungan Laut. Menurut Hadikusumah (2009), karakteristik arus laut dan kondisi pasang surut di wilayah pesisir dipengaruhi oleh morfologi pantai, letak geografis, maupun batimetri perairan. Arus merupakan perpindahan massa air yang diakibatkan beberapa faktor, diantaranya perbedaan massa jenis air, perbedaan tekanan, gaya-gaya pembangkit lain seperti gelombang dan angin. Pola dan karakteristik arus yang meliputi jenis arus dominan, kecepatan dan arah serta pola pergerakan arus laut menyebabkan kondisi suatu perairan menjadi dinamis. Pergerakan arus tersebut akan membawa materialmaterial serta sifat-sifat yang terdapat dalam badan air (Hadi, 2006).

Penelitian terkait yang pernah dilakukan tentang arus laut di beberapa wilayah Kalimantan Barat adalah Suandi et al. (2016) menganalisis pola sirkulasi arus di Perairan Pantai Sungai Duri Kabupaten Bengkayang dengan metode volume hingga, untuk memberikan informasi pola sirkulasi arus pada empat kondisi musim yang ada di Indonesia. Sementara itu Jumarang et al. (2011) melakukan kajian pola sirkulasi arus dan salinitas perairan estuari sungai Kapuas Kalimantan Barat, dengan tujuan untuk memodelkan dan mengkaji pola sirkulasi arus dan salinitas estuari sungai Kapuas yang dibangkitkan oleh pasang surut, discharge sungai dan angin. Pada studi tersebut digunakan model numerik hidrodinamika MIKE 21 untuk

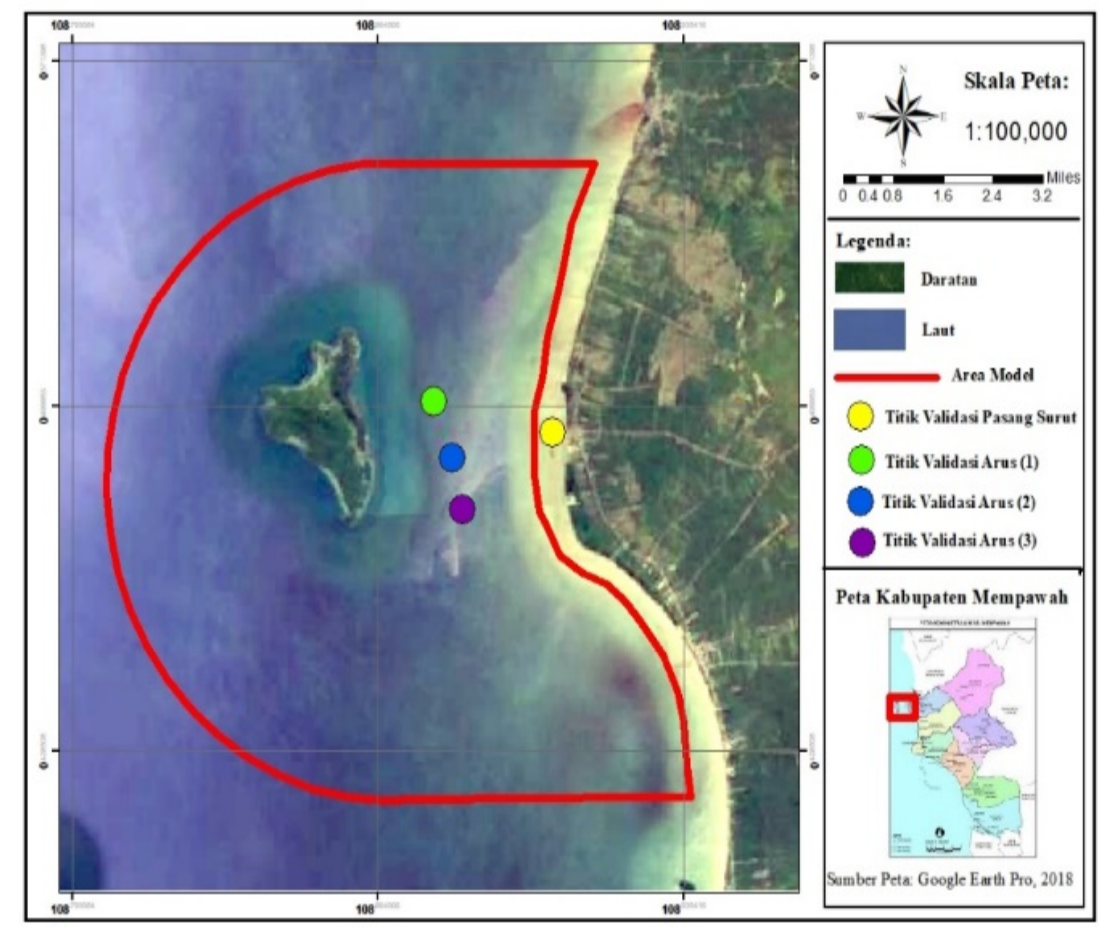

Gambar 1. Daerah kajian dalam penelitian dan domain model (warna merah) beserta titik verifikasi 
Jurnal Laut Khatulistiwa, Vol. 4. No. 1 (Febuari, 2021), Hal. 40-48.

Tabel 1. Koordinat titik pengambilan data

\begin{tabular}{ccc}
\hline Titik & $\begin{array}{c}\text { Bujur Timur } \\
(\mathrm{BT})\end{array}$ & $\begin{array}{c}\text { Lintang Utara } \\
\text { (LU) }\end{array}$ \\
\hline Pasang surut (Kuning) & $108,906^{\circ}$ & $0,495^{\circ}$ \\
Arus 1 (Hijau) & $108,878^{\circ}$ & $0,501^{\circ}$ \\
Arus 2 (Biru) & $108,882^{\circ}$ & $0,491^{\circ}$ \\
Arus 3 (Ungu) & $108,884^{\circ}$ & $0,479^{\circ}$ \\
\hline
\end{tabular}

mensimulasikan pola sirkulasi arus dan salinitas. Kushadiwijayanto et al. (2017) juga telah melakukan penelitian tentang pemodelan arus musiman di perairan Lemukutan Kalimantan Barat untuk mengkaji kondisi sirkulasi arus di sekitar perairan Pulau Lemukutan. Penelitian tersebut menggunakan metode numerik beda hingga, hidrodinamika arus pasang surut 2D yang dibangkitkan oleh stress angin.

Kajian terhadap pola arus laut yang dihubungkan dengan kondisi angin dan pasang surut merupakan hal yang penting untuk dilakukan, khususnya pada perairan Pantai Kijing yang mengalami perkembangan cukup pesat baik di sektor daratan maupun perairannya. Kondisi arus laut di suatu perairan sangat rumit untuk dipelajari secara langsung, untuk memudahkan diperlukan bantuan pemodelan hidrodinamika yang dapat melakukan simulasi pergerakan pola arus sehingga akan mempermudah dalam menganalisis kondisi perairan. Kelebihan pemodelan hidrodinamika ini yaitu dapat meramalkan pola arus sesuai waktu dan luasan yang dibutuhkan sehingga tidak harus mengambil data arus sepanjang waktu dan penempatan titik pengamatan yang banyak sehingga akan menghemat waktu, tenaga, alat dan biaya dari penelitian tersebut. Penelitian ini difokuskan untuk mengkaji bagaimana kondisi arus di perairan Pantai Kijing Kabupaten Mempawah Kalimantan Barat pada kondisi puncak musim barat dengan metode elemen hingga (finite element) menggunakan modul Resources Management Associates-2 (RMA-2).

Penelitian ini diharapkan dapat menjadi dasar bagi penelitian lebih lanjut terkait kajian arus serta bahan masukan, informasi tambahan tentang kondisi arus di Perairan Pantai Kijing, sehingga dapat digunakan untuk pengelolaan pelabuhan dan perairan disekitarnya.

\section{Metodologi Penelitian}

\subsection{Lokasi, Waktu dan Data}

Wilayah kajian dan daerah model adalah perairan Pantai Kijing, Kabupaten Mempawah Kalimantan Barat, dan titik lokasi pengukuran yang ditunjukkan pada (Tabel 1 dan Gambar 1). Pengukuran pasang surut dilakukan pada tanggal 19-21 Februari 2019, sedangkan pengukuran arus tanggal 21 Februari 2019. Proses penelitian yang meliputi set-up model, pengolahan data dan analisis dilakukan pada bulan April 2019-September 2020 di Fakultas Matematika dan Ilmu Pengetahuan Alam Universitas Tanjungpura.

Penelitian ini menggunakan data primer dan data sekunder. Data primer adalah data hasil pengukuran langsung berupa data arus dan elevasi. Pengukuran data arus dan elevasi menggunakan layang- layang arus serta tiang pasut. Sedangkan data sekunder adalah data elevasi harian tahun 2018 hasil peramalan dari Badan Informasi Geospasial (BIG), data garis pantai dari Google Earth Pro 2018, data batimetri yang diperoleh dari Pusat Teknologi Pengembangan Sumber Daya Wilayah (PTPSW) Serpong, Jakarta Selatan tahun 2017 dan data angin tahun 2008-2017 dari European Center for Medium- Range Weather Forecasts (ECMWF).

\subsection{Desain Model}

Modul perangkat lunak Surface Water Modeling System (SMS), merupakan model numeris untuk menghitung proses hidrodinamika aliran dua dimensi pada rerata kedalaman. Perangkat lunak SMS merupakan post dan pre-processing unit, sedangkan RMA2 merupakan running execution program. 
RMA-2 menggunakan metode elemen hingga Galerkin dalam menyelesaikan sistem pembentuk persamaan differensial. Prosedur diskritisasi merupakan tahapan awal yang dilakukan, yaitu membagi daerah penyelesaian (domain komputasi) menjadi sejumlah subsub domain yang lebih kecil (elemen). Pada penelitian ini, diskritisasi model menggunakan elemen gabungan segitiga (Unstructured Grid). Penyiapan data input kondisi batas (boundary condition), input parameter perairan serta diskritisasi domain model dilakukan secara interaktif menggunakan fasilitas yang disediakan di Software SMS (Cenne, 2016).

Simulasi model dijalankan selama 30 hari pada puncak musim barat (Januari). Simulasi dilakukan dengan skenario angin dan elevasi sebagai pembangkit arus. Jumlah elemen total dan node pada model berjumlah 951 dan 2.597 ,serta koefisien gesekan dasar yaitu 0,025 . Nilai kedalaman maksimum $28,59 \mathrm{~m}$ dan kedalaman minimum 1,17 $\mathrm{m}$. Verifikasi model dilakukan untuk mengetahui seberapa jauh model mampu mendekati data hasil pengukuran lapangan.

\subsection{Persamaan Hidrodinamika 2D}

Model numerik RMA-2 menyelesaikan persamaan kekekalan massa (kontinuitas) dan momentum air yang diintegrasikan terhadap kedalaman (depth- averaged) pada dua dimensi horizontal. Percepatan arah vertikal diabaikan sehingga vektor kecepatan memiliki besar dan arah yang sama sepanjang kolom air.

Persamaan kontinuitas dinyatakan sebagai berikut:

$$
\frac{\partial h}{\partial t}+h\left(\frac{\partial u}{\partial x}+\frac{\partial v}{\partial y}\right)+u \frac{\partial h}{\partial x}+v \frac{\partial h}{\partial y}=0
$$

Persamaan momentum:

Arah x:

$$
\begin{aligned}
& h \frac{\partial u}{\partial t}+h u \frac{\partial u}{\partial x}+h v \frac{\partial u}{\partial y}-\frac{h}{\rho}\left[E_{x x} \frac{\partial^{2} u}{\partial x^{2}}+E_{x y} \frac{\partial^{2} u}{\partial y^{2}}\right] \\
& +g h\left[\frac{\partial a}{\partial x}+\frac{\partial h}{\partial x}\right]+\frac{g u n^{2}}{\left(1,486^{1 / 6}\right)^{2}}\left(u^{2}+v^{2}\right)^{\frac{1}{2}} \\
& -\zeta v_{a}^{2} \cos \varphi-2 h v \omega \sin \phi=0
\end{aligned}
$$

Arah y:

$$
\begin{aligned}
& h \frac{\partial v}{\partial t}+h u \frac{\partial v}{\partial x}+h v \frac{\partial v}{\partial y}-\frac{h}{\rho}\left[E_{y x} \frac{\partial^{2} v}{\partial x^{2}}+E_{y y} \frac{\partial^{2} v}{\partial y^{2}}\right] \\
& +g h\left[\frac{\partial a}{\partial x}+\frac{\partial h}{\partial y}\right]+\frac{g v n^{2}}{\left(1,486^{1 / 6}\right)^{2}}\left(u^{2}+v^{2}\right)^{\frac{1}{2}} \\
& -\zeta v_{a}^{2} \sin \varphi-2 h u \omega \sin \phi=0
\end{aligned}
$$

Dengan: h merupakan kedalaman air (m), $\mathrm{u}$, $\mathrm{v}$ adalah kecepatan aliran dalam arah $\mathrm{x}, \mathrm{y}$ ( $\mathrm{m} / \mathrm{s}), \mathrm{x}, \mathrm{y}, \mathrm{t}$ merupakan koordinat kartesius dan waktu (s), $\rho$ adalah rapat massa zat cair, E merupakan koefisien kekentalan Eddy untuk $\mathrm{xx}$ adalah arah normal pada sumbu $\mathrm{x}$, untuk yy adalah arah normal pada sumbu $y, E_{x y}$ dan $E_{y x}$ untuk xy dan yx adalah arah shear pada tiaptiap permukaan, $g$ merupakan percepatan gravitasi $\left(\mathrm{m} / \mathrm{s}^{2}\right), \quad a$ adalah elevasi dasar perairan (m), n merupakan Manning's roughness $n$ - value (koefisien kekasaran), $\zeta$ adalah koefisien gesekan angin, $V_{a}$ merupakan kecepatan angin dan arah angin, $\varphi$ adalah arah angin, $\omega$ adalah kecepatan rotasi bumi dan $\phi$ merupakan posisi lintang geografis (Cenne, 2016). Persamaan momentum air yang digunakan hanya menghitung elevasi air akibat pasang surut. Elevasi muka air akibat pengaruh gelombang sama sekali tidak tercakup disini (Mustain, 2009).

\section{Hasil dan Pembahasan \\ 3.1. Verifikasi Model}

Perairan Pantai Kijing memiliki tipe pasut campuran tunggal. Berdasarkan perhitungan nilai bilangan formzahl dengan pembagian jumlah amplitudo pada komponen tunggal dibagi komponen ganda pasut yaitu sebesar 2,267. Hal ini didukung oleh Triatmodjo (2010) yang mengatakan bahwa pasang surut jenis ini terdapat di selat Kalimantan dan pantai Utara Jawa Barat. Tipe pasang surut campuran condong ke harian tunggal (mixed tide prevailing diurnal) artinya dalam satu hari terjadi satu kali air pasang dan satu kali air surut, tetapi kadang-kadang untuk sementara waktu terjadi dua kali pasang dan dua kali surut dengan tinggi dan periode yang sangat berbeda.

Hasil simulasi model hidrodinamika memberikan informasi tentang elevasi, kecepatan dan arah arus perairan Pantai 
Jurnal Laut Khatulistiwa, Vol. 4. No. 1 (Febuari, 2021), Hal. 40-48.

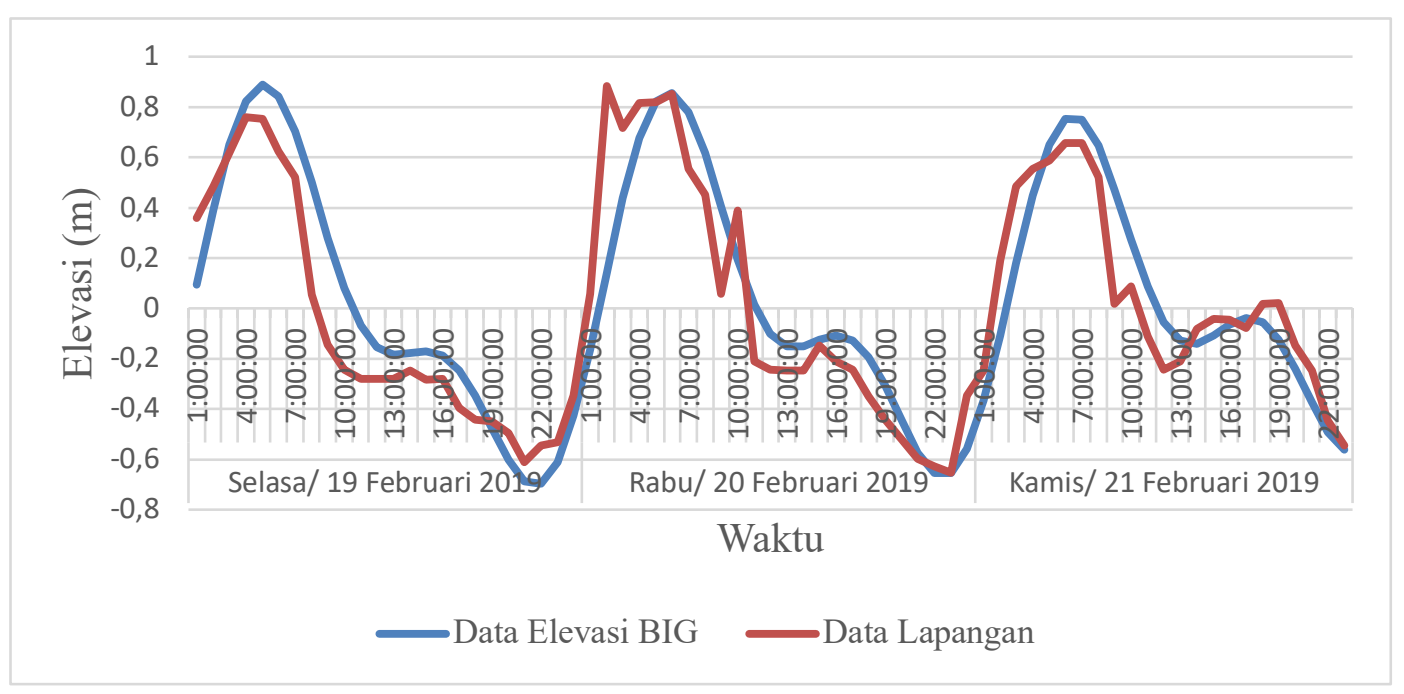

Gambar 2. Verifikasi elevasi BIG terhadap elevasi lapangan

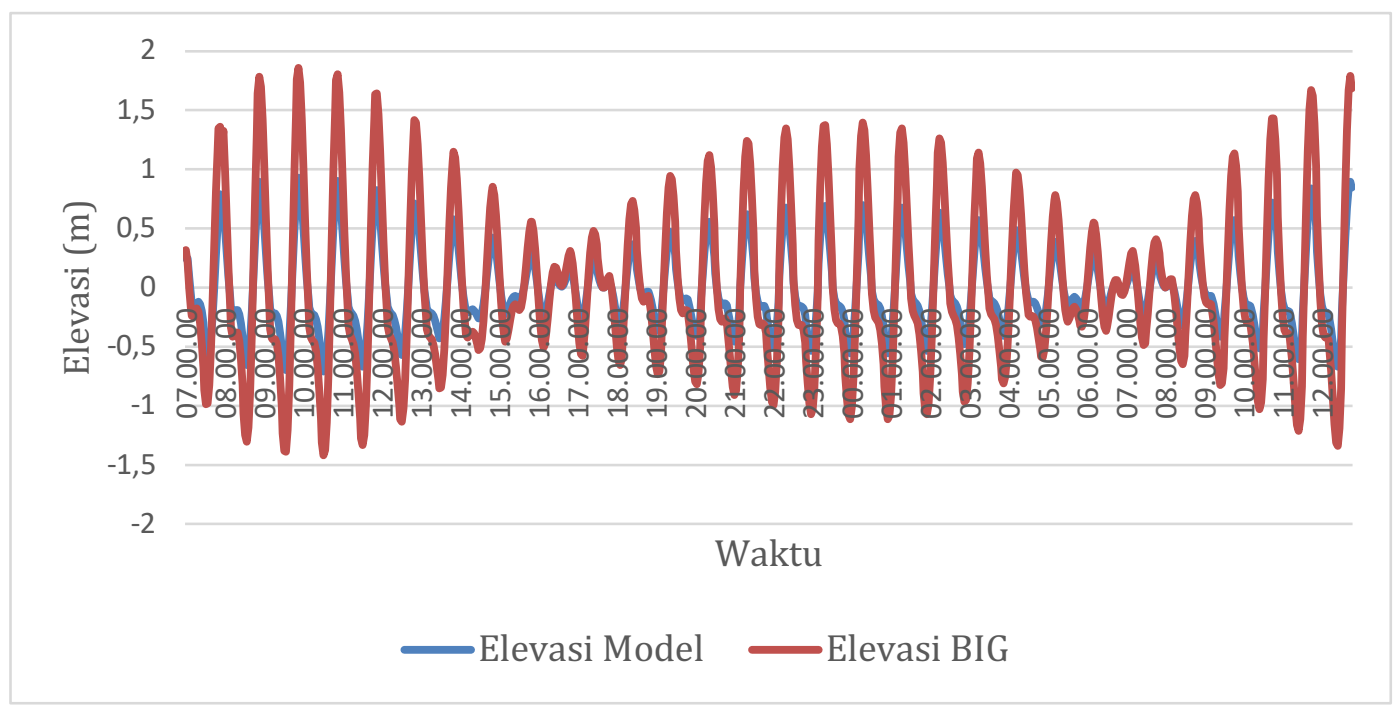

Gambar 3. Grafik perbandingan data elevasi muka air model terhadap elevasi muka air BIG

Kijing. Hasil berupa elevasi dan kecepatan arus diverifikasi dengan pengamatan lapangan yang dapat dilihat pada (Gambar 2 dan Tabel 2). Adapun (Gambar 2) yang merupakan grafik verifikasi pasut BIG dengan data pasut lapangan, meliputi data elevasi pasut selama tiga hari dari tanggal 19 s.d. 21 Februari 2019. Nilai Root Mean Square Error (RMSE) pasut BIG dan pasut lapangan sebesar 0,192. Grafik warna merah menunjukkan kondisi pasang surut hasil pengamatan di lapangan, dengan nilai pasang tertinggi $0,883 \mathrm{~m}$ dan nilai surut terendah $-0,653 \mathrm{~m}$ terjadi pada saat purnama. Grafik warna biru menunjukkan kondisi pasang surut hasil perhitungan secara astronomis pada BIG, dengan nilai pasang tertinggi 0,889 meter dan nilai surut terendah $-0,697 \mathrm{~m}$. Pada hasil pengolahan data ada kondisi dimana grafik warna merah tidak mengikuti pola grafik warna biru. Hal tersebut bisa disebabkan oleh gangguan pada saat pengambilan data di daerah penelitian, seperti saat kapal melintas dan aktivitas warga/nelayan sekitar di area perairan pantai.

Dilihat pada Gambar 3, yang merupakan grafik verifikasi elevasi muka air model dengan BIG, meliputi data elevasi muka air BIG bulan Januari terhadap data hasil model pada tanggal dan bulan yang sama sebagai pembandingnya. Nilai RMSE elevasi model dan BIG sebesar 0,036. Grafik warna merah menunjukkan kondisi elevasi dari BIG sedangkan grafik 
Jurnal Laut Khatulistiwa, Vol. 4. No. 1 (Febuari, 2021), Hal. 40-48.

Tabel 2. Perbandingan kecepatan arus dari hasil model dan pengukuran lapangan pada masing-masing titik pengamatan

\begin{tabular}{cccc}
\hline Lokasi & Pengukuran $(\mathrm{m} / \mathrm{s})$ & Model $(\mathrm{m} / \mathrm{s})$ & Selisih $(\mathrm{m} / \mathrm{s})$ \\
\hline Titik 1 & 0,03 & 0,007 & 0,023 \\
Titik 2 & 0,027 & 0,009 & 0,018 \\
Titik 3 & 0,027 & 0,009 & 0,018 \\
\hline
\end{tabular}

warna biru menunjukkan kondisi elevasi dari model. Elevasi muka air laut model memiliki nilai yang relatif sama terhadap elevasi muka air BIG di Perairan Pantai Kijing, dengan nilai pasang tertinggi $0,93 \mathrm{~m}$ dan nilai surut terendah $-0,71 \mathrm{~m}$. Namun data BIG memiliki nilai elevasi lebih tinggi daripada elevasi model. Walaupun data elevasi model memiliki elevasi lebih rendah dibandingkan data BIG, akan tetapi elevasi model mempunyai fluktuasi yang sama dengan data BIG.

Verifikasi kecepatan arus dari hasil model dan pengukuran lapangan pada masingmasing titik pengamatan yang ditunjukkan pada (Tabel 2) merupakan data kecepatan dan arah arus pada kondisi pasang tertinggi saat purnama tanggal 21 Februari 2019. Nilai RMSE arus model dan arus lapangan sebesar 0,019. Hasil verifikasi menunjukkan bahwa hasil model memiliki nilai yang lebih besar dibandingkan data pengukuran, dengan selisih pada titik 1 sebesar $0,023 \mathrm{~m}(\sim 2 \mathrm{~cm})$ sedangkan pada titik 2 dan 3 sebesar $0,018 \mathrm{~m}$ $(\sim 2 \mathrm{~cm})$. Hasil ini juga sesuai dengan penelitian yang sebelumnya dilakukan oleh Ardiani (2019) yang menyatakan bahwa hasil model lebih besar dari data pengukuran. Hal tersebut dapat disebabkan oleh kondisi perairan yaitu saat pasang purnama (spring tide) ketika pengambilan data dilakukan dan batimetri pada masukan model dengan kedalaman maksimum 28,59 m dan minimum 1,17 m yang digunakan kurang sesuai dengan kondisi kedalaman sebenarnya di lapangan. Selain itu komponen-komponen non-linier perairan dangkal memiliki kontribusi relatif besar terhadap dinamika massa air, sehingga hasil model yang benar-benar mendekati kondisi sebenarnya di lapangan sulit untuk diperoleh.

\subsection{Elevasi Muka Air Laut}

Model di simulasikan selama 30 hari untuk melihat pola elevasi dan arus saat surut menuju pasang tertinggi, saat pasang tertinggi, pasang menuju surut terendah, dan surut terendah pada puncak musim barat (Januari) yang ditunjukkan oleh (Gambar 4). Elevasi muka air laut pada saat surut menuju pasang tertinggi dititik I, II dan III masing-masing sebesar $0,6449 \mathrm{~m}, 0,6450 \mathrm{~m}$ dan $0,6449 \mathrm{~m}$, sedangkan saat pasang tertinggi dititik I, II dan

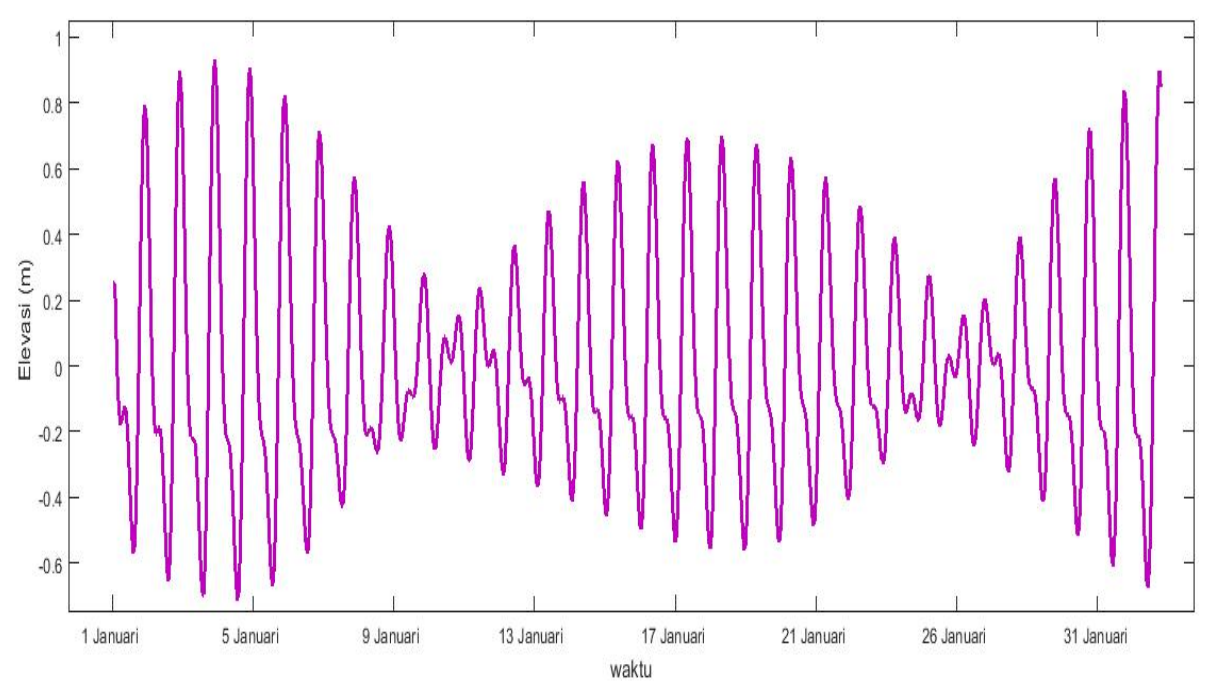

Gambar 4. Grafik elevasi muka air laut hasil simulasi model saat musim barat 
Jurnal Laut Khatulistiwa, Vol. 4. No. 1 (Febuari, 2021), Hal. 40-48.

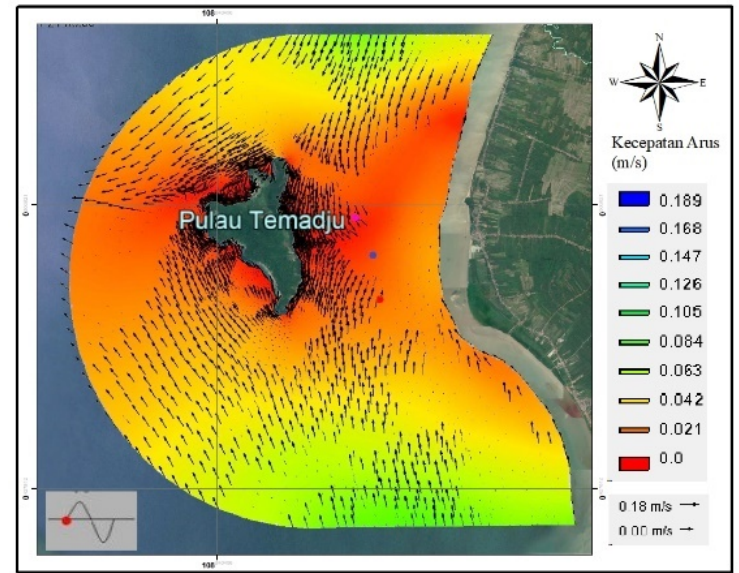

(a)

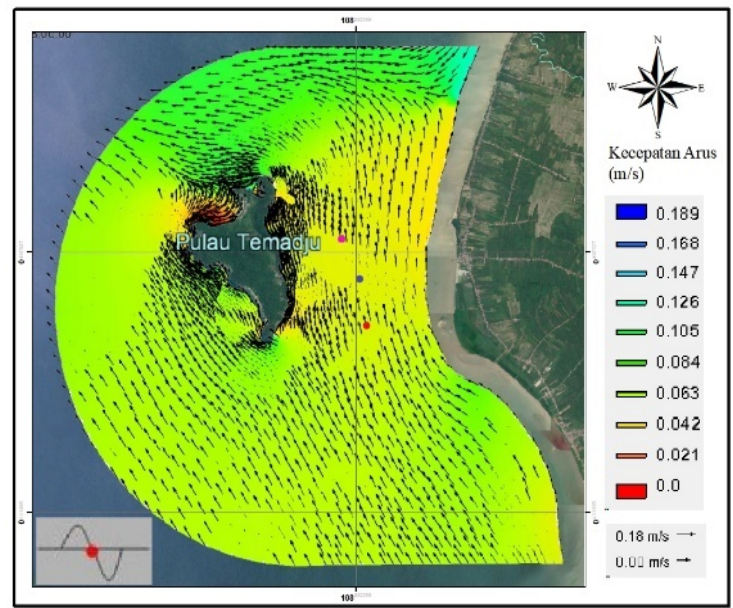

(c)

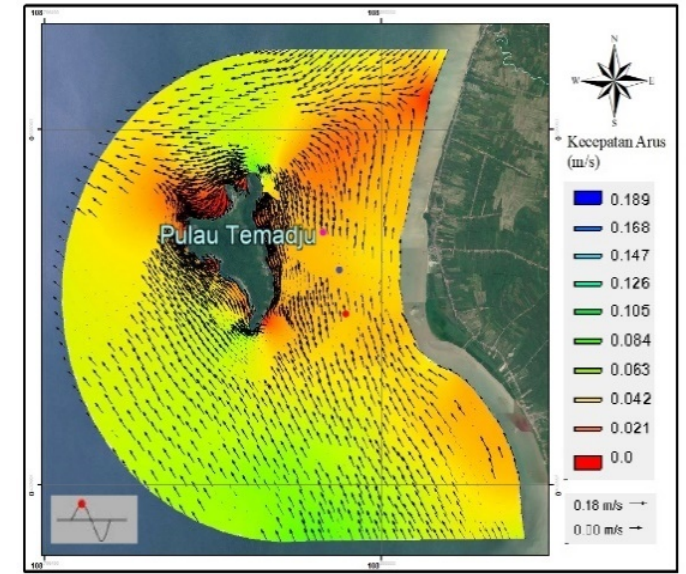

(b)

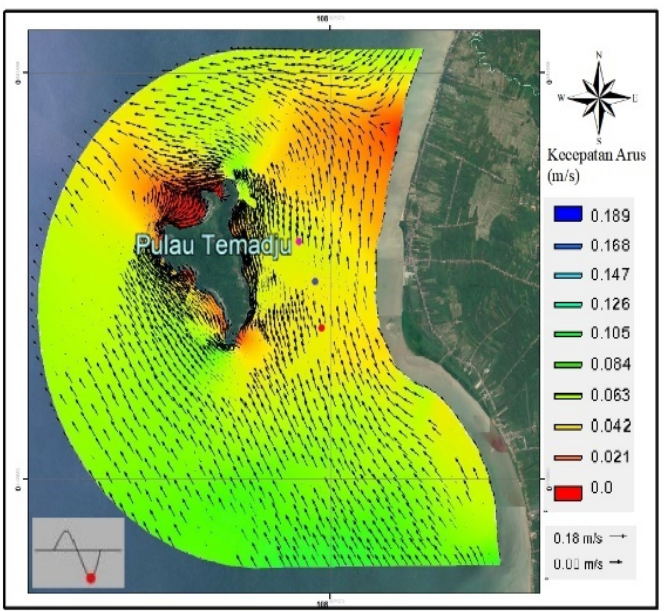

(d)

Gambar 5. Kecepatan arus hasil simulasi model musim barat (a) saat surut menuju pasang tertinggi dan (b) pasang tertinggi (c) pasang menuju surut terendah (d) surut terendah

III masing- masing sebesar 0,9307 m, 0,9306 m dan $0,9306 \mathrm{~m}$. Elevasi muka air laut pada saat pasang menuju surut terendah dititik I, II dan III masing- masing sebesar $-0,2120 \mathrm{~m},-0,2120$ $m$ dan $-0,2121 \mathrm{~m}$, sedangkan saat surut terendah dititik I sebesar -0,7105 m, dititik II 0,7106 $\mathrm{m}$ dan dititik III sebesar $-0,7107 \mathrm{~m}$.

\subsection{Kecepatan dan Arah Arus}

Kecepatan dan arah arus di perairan pantai ditunjukkan pada (Gambar 5 dan Gambar 6). Kondisi saat surut menuju pasang dititik I, II dan III masing- masing sebesar $0,004 \mathrm{~m} / \mathrm{s}$ dengan arah bergerak ke barat laut, $0,009 \mathrm{~m} / \mathrm{s}$ dengan arah bergerak ke timurtimur laut dan $0,016 \mathrm{~m} / \mathrm{s}$ dengan arah bergerak ke timur, sedangkan saat pasang tertinggi dititik I, II dan III masing-masing sebesar $0,033 \mathrm{~m} / \mathrm{s}$ dengan arah bergerak ke timur tenggara, 0,033 m/s dengan arah bergerak ke timur tenggara, dan $0,034 \mathrm{~m} / \mathrm{s}$ dengan arah bergerak ke timur tenggara. Kecepatan arus di perairan pantai saat pasang menuju surut terendah dititik I, II dan III masing-masing sebesar $0,048 \mathrm{~m} / \mathrm{s}$ dengan arah bergerak ke timur tenggara, $0,044 \mathrm{~m} / \mathrm{s}$ dengan arah bergerak ke timur tenggara, dan $0,044 \mathrm{~m} / \mathrm{s}$ dengan arah bergerak ke timur tenggara, sedangkan saat surut terendah dititik I, II dan III masing-masing sebesar 0,053 $\mathrm{m} / \mathrm{s}$ dengan arah bergerak ke timur tenggara, $0,047 \mathrm{~m} / \mathrm{s}$ dengan arah bergerak ke timur tenggara, dan $0,046 \mathrm{~m} / \mathrm{s}$ dengan arah bergerak ke timur tenggara.

Berdasarkan hasil simulasi model pada kondisi musim barat, sesuai dengan pernyataan Franchitika (2017) dalam 
Jurnal Laut Khatulistiwa, Vol. 4. No. 1 (Febuari, 2021), Hal. 40-48.

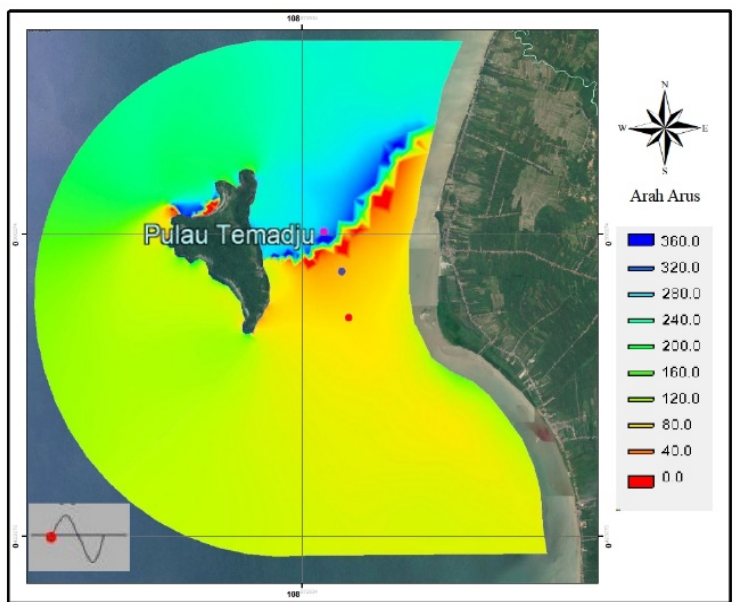

(a)

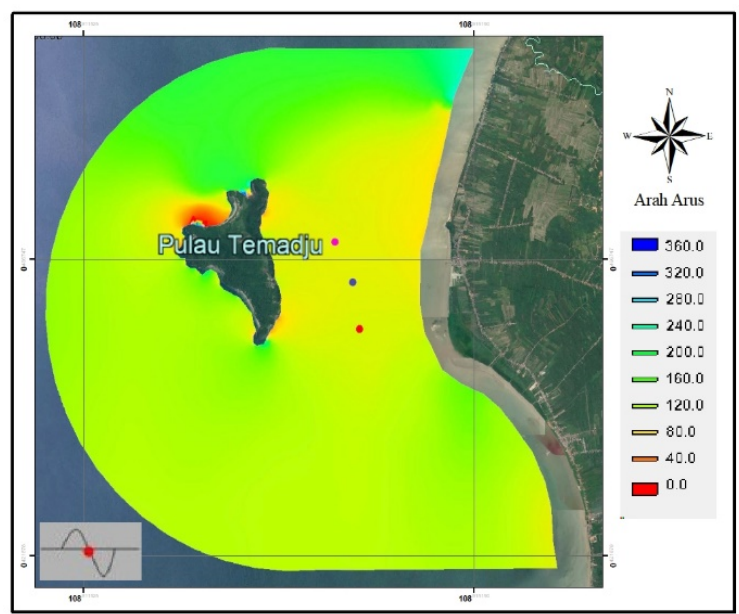

(c)

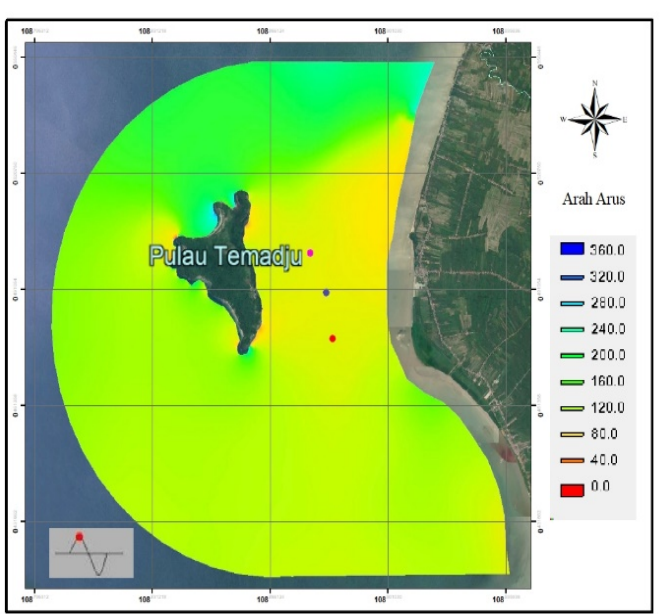

(b)

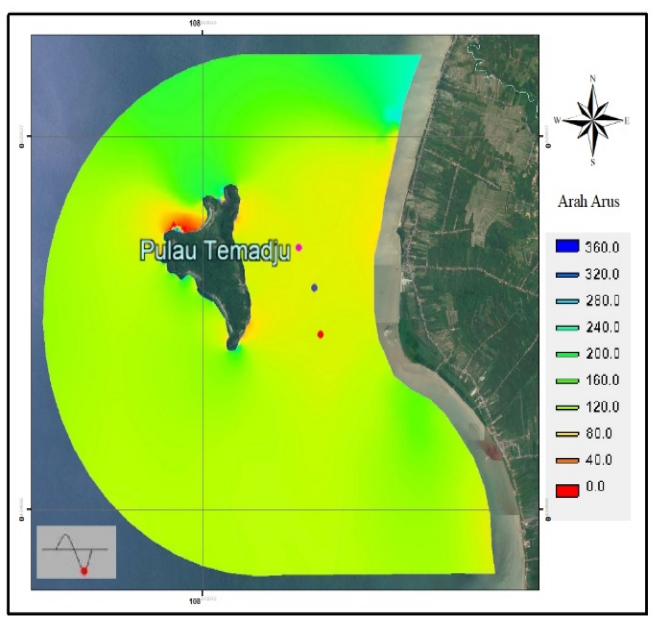

(d)

Gambar 6. Arah arus hasil simulasi model musim barat (a) saat surut menuju pasang tertinggi dan (b) pasang tertinggi (c) pasang menuju surut terendah (d) surut terendah

penelitiannya yang menyatakan bahwa pada saat laut mengalami transisi dari surut ke pasang tertinggi kecepatan arusnya cenderung naik. Angin merupakan salah satu faktor yang dapat membangkitkan arus. Berdasarkan hasil analisis kecepatan angin pada musim barat, diketahui bahwa dominasi arah angin berasal dari Utara dengan rata-rata kecepatan angin berkisar antara 3,60-5,70 m/s.

Jika kecepatan angin $10 \mathrm{~m} / \mathrm{s}$ maka kecepatan oleh angin besarnya $\approx 3 \% \mathrm{x}$ kecepatan angin. Jika merujuk pada pernyataan Hadi dan Radjawane (2009) bahwa tekanan angin yang berkerja pada permukaan laut berbanding lurus dengan kecepatan angin kuadrat, kecepatan arus permukaan yang ditimbulkan oleh angin besarnya $\approx 3 \% \mathrm{x}$ kecepatan angin. arus permukaan besarnya $\approx 30 \mathrm{~cm} / \mathrm{s}$. Maka dari hasil analisis angin tersebut kecepatan arus pada musim barat berkisar antara 0,108-0,171 $\mathrm{m} / \mathrm{s}$.

\section{Kesimpulan}

Penelitian ini menghasilkan informasi dan pemahaman mengenai kondisi arus di Perairan Pantai Kijing. Kesimpulan ini didasarkan pada analisis data pengamatan dan hasil model numerik. Perairan Pantai Kijing memiliki tipe pasut campuran tunggal (mixed tide prevailing diurnal). Hasil verifikasi pada penelitian menunjukkan bahwa hasil simulasi model pada musim barat, untuk elevasi pasang surut maupun kecepatan arus memiliki nilai 
Jurnal Laut Khatulistiwa, Vol. 4. No. 1 (Febuari, 2021), Hal. 40-48.

yang lebih besar daripada data pengukuran. Perbedaan tersebut dapat disebabkan oleh rumitnya kondisi perairan, dan masukan model yang kurang reprensentatif.

\section{Ucapan Terima Kasih}

Penulis mengucapkan terimakasih kepada orang tua, dosen pembimbing dan penguji skripsi, serta teman- teman seperjuangan atas bimbingan dan dukungannya selalu dalam penyelesaian penelitian ini. Penulis juga mengucapkan terimakasih atas bantuan data penelitian dari PTPSW Serpong, Jakarta Selatan

\section{Daftar Pustaka}

Ardiani, D., F. Susanti, Yulianti, Muliadi dan A.A. Kushadiwijayanto. 2017. Pola Pasang Surut Komponen Semi Diurnal di Teluk Tambelan Provinsi Kepulauan Riau. Prisma Fisika. 7(2): 87- 93.

Cenne, A.A. 2016. Study Karakteristik Sedimen dan Morfologi Dasar Muara Sungai Jeneberang. Skripsi. Makassar: Universitas Hasanuddin.

Direktorat Jendral Perhubungan Laut Kementrian Perhubungan. 2010. Studi Kelayakan (FS) Lokasi Kawasan Pelabuhan Internasional Sungai Kunyit, Kabupaten Pontianak. Kementrian Perhubungan Republik Indonesia. Jakarta.

Franchitika, R. 2017. Tutorial Penggunaan Software SMS 11.1 Modul RMA2 Untuk Menganalisa Pola Pergerakan Arus di Pelabuhan Belawan. Jurnal Education Building. 3(1): 73-83.

Hadikusumah. 2009. Karakteristik Gelombang dan Arus di Eretan, Indramayu. MAKARA. 13(2).

Hadi, S. 2006. Arus Laut. Bandung: Institut Teknologi Bandung (ITB).

Jumarang, M.I., Muliadi., S. Ningsih, Nining., S. Hadi, dan D. Martha. 2011. Pola Sirkulasi Arus dan Salinitas Perairan Estuari Sungai Kapuas Kalimantan Barat. Positron. 1(1): 36- 42.

Kushadiwijayanto, A.A. Apriansyah, dan N. Idiawati. 2017. Pemodelan Arus Musiman Di Perairan Lemukutan Kalimanatan Barat, Di dalam: Maison, Feri Tiona Pasaribu, Ahmad Syarkowi, Evtita, Novferma, Rosi Widia Asiani, Aulia UI Millah, Martina Asti
Rahayu (ed). Peran Sains, Teknologi dan Pendidikan MIPA dalam Menopang Sains Park, Teknopark, serta Gepopark Berbasis Agroindustri dan Lingkungan. PROSIDING SEMIRATA 2017 bidang MIPA BKS- PTN Wilayah Barat. Jambi, Indonesia. 12-14 Mei 2017. 1034-1040.

Mustain, M. 2009. Analisa Pola Arus Pasang Surut Pada Alur Pelayaran Tanjung Perak Di Selat Madura. Di dalam: Seminar Nasional Teori dan Aplikasi Teknologi Kelautan. Surabaya, Indonesia. 17 Desember 2009. 45-52.

Suandi. 2016. Analisis Pola Sirkulasi Arus di Perairan Pantai Sungai Duri Kabupaten Bengkayang Kalimantan Barat. Skripsi. Pontianak: Universitas Tanjungpura. 